\title{
Seleção para caracteres componentes de aparência e rendimento de tu- bérculo em plântulas de batata
}

\author{
Giovani Olegario da Silva ${ }^{1}$; Arione da S Pereira²; Velci Q de Souza³ Fernando Irajá Félix de Carvalho; \\ Roberto Fritsche Neto ${ }^{3}$ \\ ${ }^{1}$ Embrapa Hortaliças, C. Postal 218, 70359-970 Brasília-DF; ${ }^{2}$ Embrapa Clima Temperado, C. Postal 403, 93001-970 Pelotas-RS; ${ }^{3}$ UFPel, \\ C. Postal 354, 96010-900 Pelotas-RS; olegario@cnph.embrapa.br; arione@cpact.embrapa.br; velciq@gmail.com; \\ carvalho@ufpel.edu.br; rfneto@hotmail.com
}

\section{RESUMO}

O objetivo do presente trabalho foi verificar os ganhos esperados com a seleção correlacionada na geração de plântula, para caracteres componentes do rendimento e aparência geral de tubérculos de batata. Foram avaliadas duas populações em casa de vegetação nos cultivos de outono e primavera de 2004. Estimaram-se os ganhos esperados com a seleção direta e ganhos esperados por meio da seleção de caracteres correlacionados geneticamente. Verificouse que para alguns caracteres os ganhos correlacionados esperados podem ser obtidos na geração de plântula, sendo uma boa opção quando favoreceram caracteres com menores herdabilidades. A curvatura de tubérculo foi o caráter que proporcionou maiores ganhos correlacionados esperados para aparência geral de tubérculo.

Palavras-chave: Solanum tuberosum L., ganho correlacionado, ganho por seleção, herdabilidade, melhoramento genético.

\begin{abstract}
Selection for components of tuber appearance and yield in potato seedlings

The objective of the present research was to estimate the expected gains with correlated selection for tuber yield and general appearance component traits at the seedling stage in potato. Two populations were evaluated at seedling stage (i.e. plantlets obtained from true seeds) cultivated in glasshouse in the Fall and Spring seasons of 2004. Expected gains and gains obtained from selection of genetically correlated traits were estimated in the two experiments. For some traits the expected correlated gains could be obtained at the seedling generation, being, therefore an alternative to increase selection efficiency, especially with traits of low heritability. The tuber curvature was the trait that provided the largest expected correlated gains for general tuber appearance.
\end{abstract}

Keywords: Solanum tuberosum L., correlated gains, selection gain, heritability, genetic breeding.

\section{(Recebido para publicação em 16 de julho de 2007; aceito em 6 de junho de 2008)}

$\mathrm{A}$ seleção de plântulas, não é uma prática normalmente realizada nos programas de melhoramento de batata, devido ao questionamento de sua eficiência. Segundo vários autores, a fase de plântula deveria servir apenas para produção de tubérculos para o plantio da geração seguinte no campo (Anderson \& Howard, 1981; Brown et al., 1984). No entanto, outros consideram que a seleção para alguns caracteres na fase de plântula pode economizar recursos consideráveis em um programa de melhoramento e aumentar a frequiência de genótipos com melhores características nas fases posteriores de seleção (Swiezynski, 1978; Neele \& Louwes, 1989; Love et al., 1997; Bisognin \& Douches, 2002; Xiong et al., 2002).

A seleção indireta por meio de caracteres correlacionados permite que caracteres complexos, governados por vários genes e muitas vezes com grande ação do ambiente, possam ser me- lhorados através da seleção de caracteres menos complexos ou de mais fácil medição ou identificação, com maior herdabilidade e correlações elevadas (Goldenberg, 1968; Baker, 1986; Cruz \& Regazzi, 2001). Assim, caracteres complexos de batata poderiam ser selecionados através da seleção de seus componentes. O objetivo do presente trabalho foi verificar os ganhos em aparência geral e rendimento de tubérculo de batata, com a seleção correlacionada para seus caracteres componentes, na geração de plântula.

\section{MATERIAL E MÉTODOS}

Os experimentos foram realizados com duas populações híbridas de batata nos cultivos de outono e de primavera de 2004, na sede da Embrapa Clima Temperado. As plântulas foram originadas a partir de hibridações controladas entre genitores de batata da coleção da Embrapa Clima Temperado.
Em 2004, em casa de vegetação, sementes verdadeiras de cada população foram germinadas em sementeiras e as plântulas transplantadas para sacos plásticos contendo $2 \mathrm{~L}$ de substrato vegetal. $\mathrm{O}$ delineamento experimental foi blocos ao acaso com três repetições. Em cada repetição, foram utilizadas 15 famílias com 20 plantas e 20 famílias com 15 plantas, respectivamente para a população 1 e 2 . $\mathrm{O}$ espaçamento foi 0,10 m (entre os sacos) na linha e entre linhas. Os tubérculos foram colhidos e avaliados 77 dias após a semeadura das sementes verdadeiras.

Os caracteres de tubérculo avaliados em cada planta em ambas populações foram rendimento (g/planta); número de tubérculos/planta e massa média de tubérculos (g). Aos demais caracteres foram atribuídas notas variando de 1 a 5 , onde: formato $(1=$ redondo, $5=$ alongado); uniformidade de formato (1=desuniforme, 5=uniforme); tamanho do maior tubérculo da família (notas 


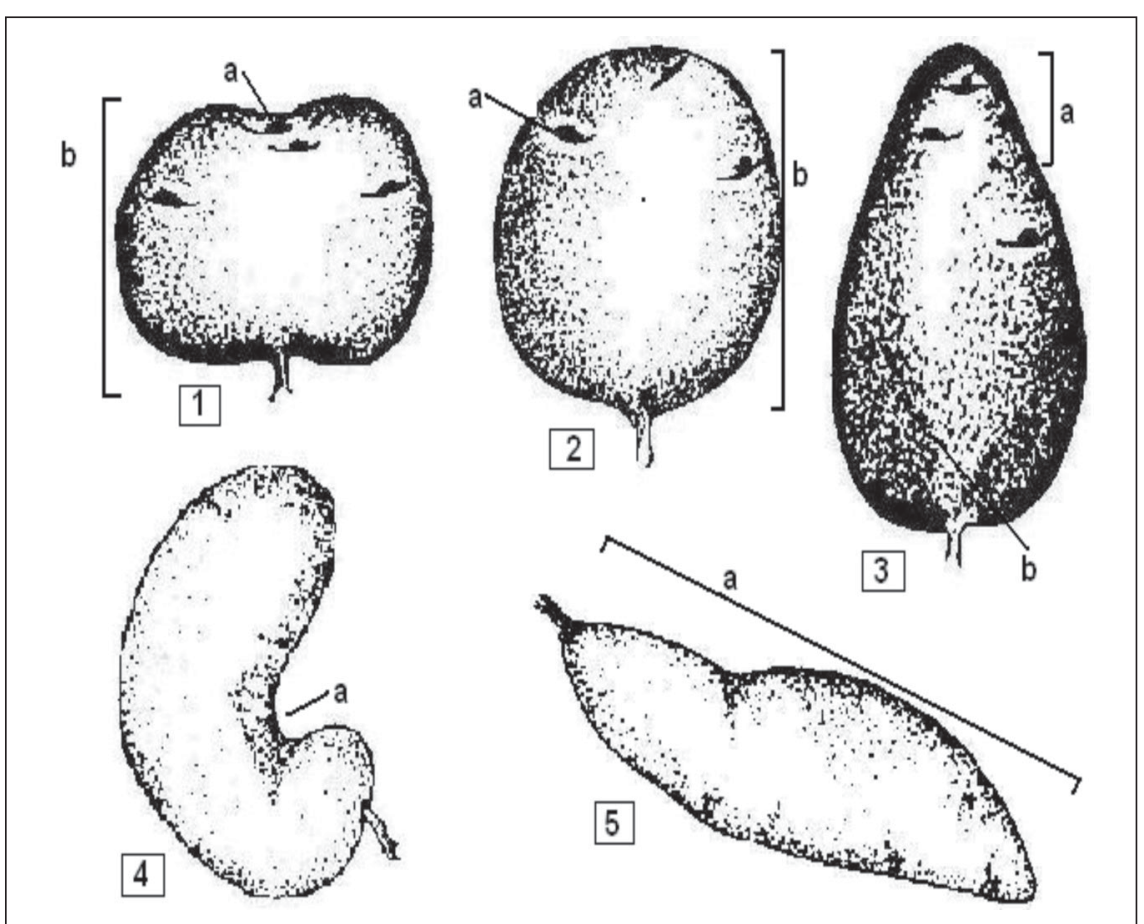

Figura 1. Identificação de caracteres de tubérculos de batata, 1a: profundidade de olhos, 1b: achatamento de tubérculo, 2a: sobrancelha, 2b: tubérculo redondo, 3a: apontamento, 3b: aspereza, 4a: curvatura, 5a: tubérculo alongado (Identification of potato tuber characters, 1a: depth eyes, $1 \mathrm{~b}$ : tuber flatness, $2 \mathrm{a}$ : eyebrow, $2 \mathrm{~b}$ : round tuber, $3 \mathrm{a}$ : pointed, $3 \mathrm{~b}$ : roughness, 4a: curvature, 5a: tuber prolonged). Pelotas, Embrapa Clima Temperado, 2004.

dadas visualmente, sem a medição dos diâmetros, em comparação com os demais tubérculos da família; $1=$ pequeno, $5=$ grande); uniformidade de tamanho (1=desuniforme, 5=uniforme); aspereza da película ( $1=$ reticulada, $5=$ lisa); profundidade dos olhos (1=profundo, $5=$ raso); sobrancelha ( $1=$ sem sobrancelhas, $5=$ extremamente proeminentes); achatamento ( $1=$ extremamente achatados, 5=tubérculos não achatados); curvatura ( $1=$ extremamente curvados, $5=$ não curvados); apontamento ( $1=\mathrm{ex}-$ tremamente apontados, $5=$ não apontados) e aparência (notas baseadas em observação visual, considerando como ideal tubérculos pouco ásperos, olhos pouco profundos, com pouca sobrancelha, não achatados, não curvados e não apontados (1=péssima, 5=excelente) (Figura 1).

Os dados foram submetidos à análise de variância e de correlação genética com a utilização do programa estatístico GENES (Cruz, 2001). Foram realizados ainda os cálculos do ganho por seleção e ganho correlacionado, expressos em porcentagem da média para possibilitar a comparação de caracteres com diferentes unidades de medida (Gopal, 2001).

A resposta correlacionada (RC) foi estimada de acordo com Falconer (1989), com índice de seleção padronizado a $10 \%$. O ganho direto por seleção para os caracteres foi estimado segundo Simmonds (1979).

As magnitudes dos coeficientes de correlação foram classificadas conforme Carvalho et al. (2004): r=0 (nula); $0<|\mathrm{r}| \leq 0.30$ (fraca); $0,30<|\mathrm{r}| \leq 0,60$ (média); $0,60<|r| \leq 0,90$ (forte); $0,90<|r| \leq 1$ (fortíssima) e $|\mathrm{r}|=1$ (perfeita).

\section{RESULTADOS E DISCUSSÃO}

De acordo com a análise de variância (dados não apresentados), os caracteres uniformidade de formato e uniformidade de tamanho de tubérculo não apresentaram significância para diferenciar as famílias analisadas na população 1 , e aspereza de película não foi significativo na população 2. Reduzida expressão destes dois primeiros caracteres na geração de plântula já havia sido relatada na literatura (Gopal, 2001).
Os coeficientes de variação genética, que são indicativos de variabilidade de ordem genética nas famílias, variaram de 1,85 a $25,12 \%$, e de 2,02 a $16,90 \%$, respectivamente, para a população 1 e 2. Situação semelhante ao coeficiente de variação genética ocorreu para a relação $\mathrm{CVg} / \mathrm{CV}$, que quando maior do que 1 indica a predominância da variação genética em relação à ambiental, e às herdabilidades, em que os menores coeficientes foram obtidos pelos caracteres que não apresentaram significância. $\mathrm{O}$ fato de que na população dois caracteres (uniformidade de tamanho e aspereza de tubérculo) terem apresentado herdabilidades medianas (0,64 e 0,63, respectivamente), mesmo não apresentando significância pela análise de variância; indica que para estes, apesar da variabilidade de ordem genética ter sido maior que a ambiental, esta não foi suficiente para possibilitar a distinção entre famílias com 5\% de probabilidade pelo teste $\mathrm{F}$ (dados não apresentados).

Em geral, as estimativas de herdabilidade foram maiores para a população 1. Em ambas populações, os caracteres de maior relação $\mathrm{CVg} / \mathrm{CV}$ e herdabilidade foram curvatura, formato e número de tubérculos. Altas estimativas de herdabilidade para formato de tubérculo têm sido reportadas na literatura (Pinto, 1994; Love et al., 1997). No entanto, em relação a número de tubérculos, têm se relatado baixas estimativas de herdabilidade, diferindo dos resultados encontrados neste trabalho (Love et al., 1997; Tai \& Young, 1984; Gopal et al., 1994).

Em relação às correlações, pode-se notar que principalmente as de magnitudes mais elevadas foram significativas em ambas populações (Tabela 1). Para se ter inferências mais consistentes nas comparações quanto aos ganhos de seleção, foram consideradas as correlações que estiveram acima da magnitude média $(r \geq 0,30)$ nas duas populações.

A aparência geral esteve correlacionada com formato, apontamento e curvatura, indicando que tubérculos com formato arredondado, e menos curvados e apontados determinam melhor aparência (Tabela 1). 
Tabela 1. Coeficientes de correlação genotípica para a população 1 (diagonal inferior) e população 2 (diagonal superior) entre componentes de aparência e rendimento de tubérculo em plântulas provenientes de casa de vegetação (genotypic correlation coefficients for population 1 (inferior diagonal) and population 2 (superior diagonal) among appearance components and tuber yield of seedlings cultivated in glass house). Pelotas, Embrapa Clima Temperado, 2004.

\begin{tabular}{|c|c|c|c|c|c|c|c|c|c|c|c|c|c|c|}
\hline Caráter $^{1}$ & APA & ASP & FOR & UFO & TAM & UTA & POL & SOB & APO & CUR & $\mathrm{ACH}$ & REN & NTU & MAM \\
\hline$\overline{\text { APA }}$ & 1 & $0,19^{*}$ & $-0,35^{*}$ & $0,30^{*}$ & $-0,04$ & 0,05 & $-0,18^{*}$ & $0,22^{*}$ & $0,49^{*}$ & $0,47^{*}$ & $-0,10^{*}$ & $0,19^{*}$ & $0,18^{*}$ & 0,04 \\
\hline ASP & $0,13^{*}$ & 1 & 0,06 & $0,12^{*}$ & 0,07 & $-0,14^{*}$ & $-0,08$ & $-0,16^{*}$ & 0,01 & $-0,05$ & 0,04 & 0,01 & $0,10^{*}$ & $-0,04$ \\
\hline FOR & $-0,34^{*}$ & $0,29^{*}$ & 1 & $-0,06$ & 0,06 & $-0,01$ & $0,35^{*}$ & $-0,18^{*}$ & $-0,45^{\star}$ & $-0,52^{*}$ & $0,27^{*}$ & $-0,15^{\star}$ & $-0,10^{*}$ & $-0,08$ \\
\hline UFO & $0,18^{*}$ & $-0,02$ & 0,04 & 1 & $-0,09$ & $0,20^{*}$ & 0,02 & $-0,01$ & $0,17^{*}$ & $0,14^{*}$ & $-0,06$ & $-0,06$ & $-0,09$ & $-0,01$ \\
\hline TAM & $-0,04$ & $0,25^{*}$ & 0,26 & $-0,01$ & 1 & $-0,20^{*}$ & $-0,18^{*}$ & $-0,15^{*}$ & $-0,07$ & $-0,11^{*}$ & $-0,17^{*}$ & $0,64^{*}$ & $-0,04$ & $0,73^{*}$ \\
\hline UTA & 0,09 & $-0,15^{*}$ & $-0,14^{*}$ & $0,33^{*}$ & $-0,19^{*}$ & 1 & $0,12^{*}$ & $0,18^{*}$ & $-0,06$ & $-0,06$ & 0,08 & $-0,17^{*}$ & $-0,34^{*}$ & 0,08 \\
\hline POL & $-0,07$ & $-0,13^{*}$ & 0,09 & $0,26^{*}$ & $-0,05$ & 0,08 & 1 & 0,09 & $-0,21^{*}$ & $-0,24^{*}$ & $0,15^{*}$ & $-0,31^{*}$ & $-0,18^{*}$ & $-0,19^{*}$ \\
\hline SOB & $0,37^{*}$ & $-0,14^{*}$ & $-0,32^{*}$ & 0,09 & $-0,26^{*}$ & $0,14^{*}$ & $0,19^{*}$ & 1 & $0,17^{*}$ & $0,13^{*}$ & $-0,06$ & $-0,03$ & $0,11^{*}$ & $-0,15^{*}$ \\
\hline APO & $0,55^{*}$ & $-0,19^{*}$ & $-0,48^{*}$ & 0,08 & $-0,25^{*}$ & 0,08 & $-0,01$ & $0,31^{*}$ & 1 & 0,75 & $-0,23^{*}$ & $0,11^{*}$ & $0,11^{*}$ & $-0,02$ \\
\hline CUR & $0,54^{*}$ & $-0,25^{*}$ & $-0,55^{*}$ & 0,01 & $-0,24^{*}$ & 0,07 & $-0,14^{*}$ & $0,25^{\star}$ & $0,60^{*}$ & 1 & $-0,20^{*}$ & $-0,02$ & $-0,08$ & $-0,20^{*}$ \\
\hline $\mathrm{ACH}$ & 0,08 & 0,03 & 0,01 & 0,01 & $-0,26^{*}$ & 0,03 & $-0,09$ & $-0,06$ & $-0,02$ & 0,07 & 1 & $-0,27^{*}$ & $-0,07$ & $-0,21^{*}$ \\
\hline REN & $0,15^{*}$ & $0,28^{*}$ & 0,07 & $-0,14^{*}$ & $0,65^{*}$ & $-0,14^{*}$ & $-0,25^{*}$ & $-0,10^{*}$ & $-0,01$ & $-0,05$ & $-0,18^{*}$ & 1 & $0,45^{*}$ & $0,62^{*}$ \\
\hline NTU & $0,15^{*}$ & $0,18^{*}$ & 0,05 & $-0,17^{*}$ & $-0,07$ & $-0,37^{*}$ & $-0,16^{*}$ & 0,04 & 0,03 & 0,04 & 0,01 & $0,40^{*}$ & 1 & $-0,34^{*}$ \\
\hline MAM & $-0,04$ & $0,12^{*}$ & $0,13^{*}$ & $-0,01$ & $0,67^{*}$ & $0,24^{*}$ & $-0,12^{*}$ & $-0,15^{*}$ & $-0,11^{*}$ & $-0,14^{*}$ & $-0,19^{*}$ & $0,52^{*}$ & $-0,48^{*}$ & 1 \\
\hline
\end{tabular}

${ }^{1}$ APA: aparência; ASP: aspereza; FOR: formato; UFO: uniformidade de formato; TAM: tamanho; UTA: uniformidade de tamanho; POL: profundidade de olho; SOB: sobrancelha; APO: apontamento; CUR: curvatura de tubérculo; ACH: achatamento de tubérculo, REN: rendimento; NTU: número de tubérculos; MAM: massa média. (APA: appearance; ASP: roughness; FOR: shape; UFO: shape uniformity; TAM: size; UTA: size uniformity; POL: eye depth; SOB: eyebrow; APO: pointed; CUR: tuber curvature; ACH: tuber flatness; REN: yield; NTU: tuber number; MAM: medium mass). *Significativo a 5\% de probabilidade de erro, teste T (*Significant to 5\% of error probability, T test).

Tabela 2. Respostas correlacionadas esperadas de seleção para caracteres de tubérculo $\left({ }^{1}\right)$ pela seleção nos caracteres $\left({ }^{2}\right)$ em duas populações de plântulas de batata (correlated expected selection responses for tuber traits (1) by selection in the traits (2) in two seedlings potato populations). Pelotas, Embrapa Clima Temperado, 2004.

\begin{tabular}{|c|c|c|c|c|c|c|c|c|c|c|c|c|c|c|c|}
\hline Caráter & $\begin{array}{l}\text { Popul- } \\
\text { ação }\end{array}$ & APA $^{2}$ & ASP & FOR & UFO & TAM & UTA & POL & SOB & APO & CUR & $\mathrm{ACH}$ & REN & NTU & MAM \\
\hline \multirow[t]{2}{*}{$\mathrm{SOB}^{1}$} & 1 & 67,54 & $-24,93$ & $-63,02$ & 5,75 & $-35,39$ & 16,37 & 29,87 & & 50,26 & 54,49 & $-10,59$ & $-1,14$ & 2,02 & $-5,16$ \\
\hline & 2 & 7,42 & $-5,35$ & $-6,66$ & $-0,29$ & $-4,38$ & 6,07 & 2,99 & & 1,03 & 5,14 & $-0,05$ & $-0,06$ & 3,62 & $-1,50$ \\
\hline \multirow[t]{2}{*}{ APO } & 1 & 115,98 & $-40,68$ & $-110,2$ & 4,52 & $-39,82$ & 12,86 & $-2,07$ & 71,08 & & 183,78 & $-7,49$ & $-0,44$ & 4,76 & $-4,56$ \\
\hline & 2 & 26,79 & 0,54 & $-26,99$ & 7,88 & $-3,31$ & $-3,28$ & $-11,30$ & 9,72 & & 11,29 & $-8,13$ & 59,18 & 5,36 & $-0,30$ \\
\hline \multirow[t]{2}{*}{ CUR } & 1 & 87,53 & $-36,80$ & $-88,66$ & 1,12 & $-32,28$ & 7,14 & $-18,39$ & 45,59 & 108,72 & & 9,11 & $-0,62$ & 1,74 & $-3,33$ \\
\hline & 2 & 25,12 & $-2,65$ & $-30,49$ & 6,34 & $-5,09$ & $-3,21$ & $-12,63$ & 7,27 & 41,37 & & $-1,35$ & $-0,84$ & $-0,40$ & $-3,34$ \\
\hline \multirow[t]{2}{*}{$\mathrm{ACH}$} & 1 & 15,67 & 6,67 & 2,36 & $-0,74$ & $-44,78$ & 7,91 & $-16,30$ & $-18,65$ & $-9,33$ & 19,17 & & $-2,25$ & 0,91 & $-7,44$ \\
\hline & 2 & $-1,44$ & 0,57 & 4,27 & $-0,73$ & $-2,12$ & 1,15 & 2,13 & $-0,90$ & $-3,47$ & $-3,38$ & & $-0,02$ & $-1,19$ & $-10,53$ \\
\hline \multirow[t]{2}{*}{ REN } & 1 & 20,72 & 41,19 & 10,07 & $-5,81$ & 79,73 & $-13,52$ & $-31,93$ & $-18,26$ & $-4,98$ & $-11,95$ & $-20,50$ & & 483,99 & 257,47 \\
\hline & 2 & 19,65 & 1,03 & $-17,01$ & $-5,26$ & 57,32 & $-17,58$ & $-31,55$ & $-3,24$ & 11,90 & $-32,74$ & $-20,94$ & & 780,30 & 339,12 \\
\hline \multirow[t]{2}{*}{ NTU } & 1 & 30,54 & 34,69 & 11,49 & $-10,84$ & $-16,37$ & $-54,00$ & $-25,83$ & 6,82 & 11,36 & 7,01 & 1,75 & 101,91 & & $-50,41$ \\
\hline & 2 & 7,59 & 4,18 & $-4,62$ & $-3,22$ & $-1,46$ & $-14,34$ & $-7,47$ & 4,85 & 4,85 & $-3,96$ & $-2,53$ & 19,56 & & $-1,28$ \\
\hline \multirow[t]{2}{*}{ MAM } & 1 & $-5,73$ & 11,38 & 13,27 & 0,38 & 63,01 & 17,81 & $-10,43$ & $-19,09$ & $-11,93$ & $-14,71$ & $-15,65$ & 59,43 & $-55,26$ & \\
\hline & 2 & 5,30 & $-5,26$ & $-11,63$ & $-1,12$ & 83,77 & 10,60 & $-24,78$ & $-20,79$ & $-2,77$ & $-32,63$ & $-20,87$ & 84,68 & $-53,42$ & \\
\hline
\end{tabular}

APA: aparência; ASP: aspereza; FOR: formato; UFO: uniformidade de formato; TAM: tamanho; UTA: uniformidade de tamanho; POL: profundidade de olho; SOB: sobrancelha; APO: apontamento; CUR: curvatura de tubérculo; ACH: achatamento de tubérculo; REN: rendimento; NTU: número de tubérculos; MAM: massa média. (APA: appearance; ASP: roughness; FOR: shape; UFO: shape uniformity; TAM: size; UTA: size uniformity; POL: eye depth; SOB: eyebrow; APO: pointed; CUR: tuber curvature; ACH: tuber flatness; REN: yield; NTU: tuber number; MAM: medium mass).

Maiores ganhos correlacionados com a melhoria da aparência foram estimados em relação à curvatura, com ganho indireto de 87,53 e $25,12 \%$ na população 1 e 2 , respectivamente (Tabela 2), valores muito expressivos se considerar que o ganho pela seleção direta para este caráter foi estimado em 68,87 e $70,99 \%$.

Quanto ao formato de tubérculo, além da correlação citada anteriormente com aparência, foi também correlacionado com apontamento e curvatura (Tabela 1). Com ganhos correlacionados mais fortes em relação à curvatura $-100,5 \%$ e -13,63\% nas duas populações, respectivamente, portanto a seleção em tubérculos menos curva- 
Tabela 3. Respostas correlacionadas esperadas de seleção para caracteres de tubérculo ( $\left.{ }^{1}\right)$ pela seleção nos caracteres ( $\left.{ }^{2}\right)$ em duas populações de plântulas de batata. (correlated expected selection responses for tuber traits (1) by selection in the traits (2) in two seedlings potato populations). Pelotas, Embrapa Clima Temperado, 2004.

\begin{tabular}{|c|c|c|c|c|c|c|c|c|c|c|c|c|c|c|c|}
\hline Caráter & $\begin{array}{l}\text { Popul- } \\
\text { ação }\end{array}$ & APA $^{2}$ & ASP & FOR & UFO & TAM & UTA & POL & SOB & APO & CUR & $\mathrm{ACH}$ & REN & NTU & MAM \\
\hline \multirow[t]{2}{*}{$\overline{\mathrm{APA}^{1}}$} & 1 & & 8,92 & $-23,64$ & 5,25 & $-3,66$ & 3,90 & $-8,59$ & 56,51 & 68,61 & 87,53 & 7,44 & 1,08 & 7,57 & $-1,29$ \\
\hline & 2 & & 1,82 & $-23,40$ & 1,04 & $-1,83$ & 3,45 & $-7,29$ & 9,38 & 3,00 & 22,47 & $-2,88$ & 0,45 & 7,16 & 0,49 \\
\hline \multirow[t]{2}{*}{ ASP } & 1 & 11,67 & & 28,72 & $-0,85$ & 22,87 & $-8,24$ & $-22,36$ & $-27,31$ & $-31,51$ & $-48,19$ & 4,15 & 2,81 & 11,26 & 3,37 \\
\hline & 2 & 12,91 & & 1,27 & 5,96 & $-0,29$ & $-12,23$ & $-4,10$ & $-8,63$ & 0,59 & $-0,32$ & 1,46 & 0,03 & 5,03 & $-0,61$ \\
\hline \multirow[t]{2}{*}{ FOR } & 1 & $-26,81$ & 24,87 & & 1,57 & 20,99 & $-6,98$ & 13,68 & $-59,78$ & $-73,92$ & $-100,5$ & 1,27 & 0,60 & 3,23 & 3,40 \\
\hline & 2 & $-11,70$ & 1,99 & & $-0,11$ & 1,50 & $-0,03$ & 7,77 & $-4,21$ & $-11,51$ & $-13,63$ & 0,14 & $-0,19$ & $-2,18$ & $-0,53$ \\
\hline \multirow[t]{2}{*}{ UFO } & 1 & 2,81 & $-0,35$ & 0,74 & & $-0,13$ & 2,59 & 6,08 & 2,57 & 1,43 & 0,60 & $-0,19$ & $-0,16$ & $-1,44$ & 0,05 \\
\hline & 2 & 10,20 & 4,05 & $-2,24$ & & $-0,35$ & 10,15 & 0,06 & $-0,31$ & 5,82 & 4,91 & $-1,27$ & $-19,33$ & $-2,63$ & $-0,09$ \\
\hline \multirow[t]{2}{*}{ TAM } & 1 & $-3,66$ & 17,47 & 18,51 & $-0,24$ & & $-7,31$ & $-8,36$ & $-29,61$ & $-23,56$ & $-32,28$ & $-21,28$ & 1,89 & $-4,06$ & 14,24 \\
\hline & 2 & $-1,45$ & $-2,51$ & 2,38 & $-2,76$ & & $-1,17$ & $-4,99$ & $-0,26$ & $-2,23$ & $-3,60$ & $-3,35$ & 1,04 & $-0,10$ & 6,06 \\
\hline \multirow[t]{2}{*}{ UTA } & 1 & 2,08 & $-3,36$ & $-3,29$ & 2,59 & $-3,91$ & & 3,79 & 7,32 & 4,07 & 3,82 & 2,01 & $-0,83$ & $-7,15$ & 2,15 \\
\hline & 2 & 3,23 & $-8,98$ & $-0,71$ & 10,96 & $-11,19$ & & 0,76 & 7,18 & $-0,34$ & $-2,68$ & 2,16 & $-0,38$ & $-12,64$ & 10,00 \\
\hline \multirow[t]{2}{*}{ POL } & 1 & $-6,49$ & $-12,91$ & 9,12 & 8,60 & $-6,32$ & 5,36 & & 18,89 & $-0,93$ & $-13,90$ & $-5,86$ & $-1,26$ & $-4,84$ & $-1,78$ \\
\hline & 2 & $-7,29$ & $-3,21$ & 15,55 & 0,69 & $-6,31$ & 4,86 & & 0,70 & $-9,64$ & $-1,20$ & 4,26 & $-0,72$ & $-7,04$ & $-2,27$ \\
\hline
\end{tabular}

APA: aparência; ASP: aspereza; FOR: formato; UFO: uniformidade de formato; TAM: tamanho; UTA: uniformidade de tamanho; POL: profundidade de olho; SOB: sobrancelha; APO: apontamento; CUR: curvatura de tubérculo; ACH: achatamento de tubérculo; REN: rendimento; NTU: número de tubérculos; MAM: massa média. (APA: appearance; ASP: roughness; FOR: shape; UFO: shape uniformity; TAM: size; UTA: size uniformity; POL: eye depth; SOB: eyebrow; APO: pointed; CUR: tuber curvature; ACH: tuber flatness; REN: yield; NTU: tuber number; MAM: medium mass).

dos conduz a tubérculos mais arredondados (Tabela 3).

Tamanho de tubérculos apresentou alta correlação com rendimento e massa média $(0,64$ e 0,74 , respectivamente, para a população 1$)$ e $(0,65$ e 0,67 , respectivamente, para a população 2 ). Portanto, esteve associado mais fortemente com massa média. Com Solanum tuberosum spp. andigena cultivada a campo (Thompson et al., 1983) também verificaram incremento no rendimento com aumento no tamanho de tubérculo.

A uniformidade de tamanho de tubérculo, nas duas populações mostrou correlações médias e muito semelhantes com número de tubérculos (Tabela 3). A diminuição no número de tubérculos influencia em $7,15 \%$ e $12,64 \%$ no aumento da uniformidade de tamanho na geração posterior, sendo uma boa opção de seleção, considerando que número de tubérculos apresentou elevado valor de herdabilidade.

Apontamento e curvatura de tubérculo foram correlacionados fortemente entre si, com valores de $r=0,75$ e 0,60 nas duas populações (Tabela 1), com maiores ganhos correlacionados entre os mesmos. Para tubérculos menos apontados, o ganho pela seleção em tubérculos menos curvados foi estimado em
$183,78 \%$ e $11,29 \%$, respectivamente para a população 1 e 2. Já os ganhos para curvatura de tubérculo pela seleção em tubérculos menos apontados, foram de $108,72 \%$ e $41,37 \%$ nas duas populações, respectivamente (Tabela 2 ).

Rendimento e massa média de tubérculos foram correlacionados entre si. Além disso, estes apresentaram correlação com número de tubérculos, rendimento e para massa média, nas duas populações. Maiores rendimentos foram acompanhados de maiores massas médias e maior número de tubérculos. No entanto, plantas com maior número de tubérculos tiveram menor massa média (Tabela 1).

A massa média proporcionou ganhos correlacionados acima de $50 \%$ e bastante semelhantes em relação a tamanho, rendimento e número de tubérculos, demonstrando um equilíbrio que deve existir no momento da seleção destes três últimos caracteres (Tabela 2). Estes resultados estão de acordo com Maris (1988), que verificou acréscimo no rendimento com aumentos em número e massa média de tubérculos. Concordam também com alguns autores que encontraram correlações significativas de rendimento com número e massa média de tubérculos (Gopal et al., 1994; Gopal,
2001; Rodrigues \& Pereira, 2003; Gaur et al., 1978). Com plântulas produzidas a campo, correlações significativas entre rendimento e número de tubérculos também foram relatadas (Pinto et al., 1994; Thompson et al., 1983).

Para os caracteres aspereza, profundidade de olho e sobrancelha, que não apresentaram correlação com outros caracteres de forma consistente nas duas populações, a seleção direta seria a melhor opção.

$\mathrm{O}$ achatamento e uniformidade de formato, que não apresentaram significância no conjunto dos períodos e não foram correlacionados consistentemente com outros caracteres, a seleção na geração de plântula cultivadas em casa de vegetação não proporcionaria ganhos consideráveis.

Os resultados obtidos revelam que a seleção correlacionada na geração de plântula, para alguns caracteres é uma boa opção quando favorece caracteres com menores herdabilidades, como ganhos para aparência e formato selecionando curvatura, ganhos pela seleção em achatamento para favorecer uma menor curvatura e vice versa e para maior tamanho selecionando massa média, rendimento e número de tubérculos. Verificou-se ainda que a seleção 
para curvatura de tubérculo proporciona o maior ganho correlacionado em aparência geral de tubérculo.

\section{REFERÊNCIAS}

ANDERSON JAD; HOWARD HW. 1981. Effectiveness of selection in the early stages of potato breeding programmes. Potato Research 24: 289-299.

BAKER RJ. 1986. Selection indices in plant breeding. Florida: CRC. 218p.

BISOGNIN DA; DOUCHES DS. 2002. Early generation selection for potato tuber quality in progenies of late blight resistant parents. Euphytica 127: 1-9.

BROWN J; CALIGARI PDS; MACKAY GR; SWAN GEL. 1984. The efficiency of seedling selection by visual preference in a potato breeding programme. Journal of Agricultural Science 103: 339-346.

CARVALHO FIF; LORENCETTI C; BENIN G. 2004. Estimativas e implicações da correlação no melhoramento vegetal. Pelotas: Ed. Universitária da UFPel. 142p.

CRUZ CD. 2001. Programa genes, aplicativo computacional em genética e estatística. Viçosa: UFV. 648p.

CRUZ CD; REGAZZI AJ. 2001. Métodos biométricos aplicados ao melhoramento genético. Viçosa: UFV. 390p.
FALCONER DS. 1989. Introduction to quantitative genetics. New York: Longman Group. 438 p.

GAUR PC; KISHORE H; GUPTA PK.1977. Studies on character association in potatoes. Journal of Agricultural Science 90: 215-219.

GOLDENBERG JB. 1968. El empleo de la correlación en el mejoramento genético de las plantas. Fitotecnia Latinoamericana 5: 1-8.

GOPAL J; GAUR PC; RANA MS. 1994. Hereditability, intra- and inter-generation associations between tuber yield and its components in potato (Solanum tuberosum $\mathrm{L}$.). Plant Breeding 112: 80-83.

GOPAL J. 2001. Genetic parameters and character associations for family selection in potato breeding programmes. Journal of Genetics \& Breeding 55: 201-208.

LOVE SL; WERNER BK; PAVEK JJ. 1997. Selection for individual traits in the early generations of a potato breeding program dedicated to producing cultivars with tubers having long shape and russet skin. American Potato Journal 74: 199-213.

MARIS B. 1988. Correlations within and between characters between and within generations as a measure for the early generation selection in potato breeding. Euphytica 37: 205-209.

NEELE AEF; LOUWES KM. 1989. Early selection for chip quality and dry matter content in potato seedling populations in greenhouse or screenhouse. Potato Research 32: 293-300.
PINTO CAB; VANDERLEI IRV; ROSSI MS. 1994. Eficiência da seleção nas primeiras gerações clonais em batata (Solanum tuberosum L.). Pesquisa Agropecuária Brasileira 29: 771-778.

RODRIGUES AFS; PEREIRA AS. 2003. Correlações inter e intragerações e herdabilidade de cor de chips, matéria seca e produção de batata. Pesquisa Agropecuária Brasileira 38: 599-604.

SIMMONDS NW. 1979. Principles of crop improvement. New York: Longman. 408p.

SWIEZYNSKI KM. 1978. Selection of individual tubers in potato breeding. Theoretical and Applied Genetics 53: 71-80.

TAI GCC; YOUNG DA. 1984. Early generation selection for important agronomic characteristics in a potato breeding population. American Potato Journal 61: 419-434.

THOMPSON PG; MENDOZA HA; PLAISTED RL. 1983. Estimation of genetic parameters for characters related to potato propagation by true seed (TPS) in an andigena population. American Potato Journal 60: 393-401.

XIONG X; TAI GCC; SEABROOK JEA. 2002. Effectiveness of selection for quality traits during the early stage in the potato breeding population. Plant Breeding 121: 441-444. 